\title{
Modelling the genesis of equatorial podzols: age and implications for carbon fluxes
}

\author{
Cédric Doupoux ${ }^{1}$, Patricia Merdy ${ }^{1}$, Célia Régina Montes $^{2}$, Naoise Nunan ${ }^{3}$, Adolpho José Melfi ${ }^{4}$, \\ Osvaldo José Ribeiro Pereira ${ }^{2}$, and Yves Lucas ${ }^{1}$ \\ ${ }^{1}$ Université de Toulon, PROTEE Laboratory, EA 3819, CS 60584, 83041 Toulon Cedex 9, France \\ ${ }^{2}$ University of São Paulo, NUPEGEL, CENA, Av. Centenário, 303, CEP 13416-903 Piracicaba, SP, Brazil \\ ${ }^{3}$ CNRS, iEES Paris, 78850 Thiverval-Grignon, France \\ ${ }^{4}$ University of São Paulo, IEE, ESALQ, São Paulo, SP, Brazil
}

Correspondence to: Cédric Doupoux (cedric.doupoux@gmail.com)

Received: 14 December 2016 - Discussion started: 18 January 2017

Revised: 5 April 2017 - Accepted: 11 April 2017 - Published: 12 May 2017

\begin{abstract}
Amazonian podzols store huge amounts of carbon and play a key role in transferring organic matter to the Amazon River. In order to better understand their C dynamics, we modelled the formation of representative Amazonian podzol profiles by constraining both total carbon and radiocarbon. We determined the relationships between total carbon and radiocarbon in organic $\mathrm{C}$ pools numerically by setting constant $\mathrm{C}$ and ${ }^{14} \mathrm{C}$ inputs over time. The model was an effective tool for determining the order of magnitude of the carbon fluxes and the time of genesis of the main carboncontaining horizons, i.e. the topsoil and deep Bh. We performed retrocalculations to take into account the bomb carbon in the young topsoil horizons (calculated apparent ${ }^{14} \mathrm{C}$ age from 62 to 109 years). We modelled four profiles representative of Amazonian podzols, two profiles with an old $\mathrm{Bh}$ (calculated apparent ${ }^{14} \mathrm{C}$ age $6.8 \times 10^{3}$ and $8.4 \times 10^{3}$ years) and two profiles with a very old $\mathrm{Bh}$ (calculated apparent ${ }^{14} \mathrm{C}$ age $23.2 \times 10^{3}$ and $25.1 \times 10^{3}$ years). The calculated fluxes from the topsoil to the perched water table indicate that the most waterlogged zones of the podzolized areas are the main source of dissolved organic matter found in the river network. It was necessary to consider two Bh carbon pools to accurately represent the carbon fluxes leaving the $\mathrm{Bh}$ as observed in previous studies. We found that the genesis time of the studied soils was necessarily longer than $15 \times 10^{3}$ and $130 \times 10^{3}$ years for the two younger and two older Bhs, respectively, and that the genesis time calculated considering the more likely settings runs to around $15 \times 10^{3}-25 \times 10^{3}$ and $150 \times 10^{3}-250 \times 10^{3}$ years, respectively.
\end{abstract}

\section{Introduction}

Podzols are soils characterized by the formation of a sandy, bleached horizon (E horizon) overlying a dark horizon with illuviated organic matter as well as $\mathrm{Fe}$ and $\mathrm{Al}$ compounds (spodic or Bh horizon). In wet tropical areas podzols can be very deep, with $\mathrm{E}$ horizons thicker than $10 \mathrm{~m}$ and $\mathrm{Bh}$ horizons thicker than $4 \mathrm{~m}$ (Chauvel et al., 1987; Dubroeucq and Volkoff, 1998; Montes et al., 2011). This means that they can store huge quantities of organic matter: Montes et al. (2011) estimated the $\mathrm{C}$ stocks in Amazonian podzols to be around 13.6 Pg C.

This $\mathrm{C}$ constitutes a non-negligible portion of the $\mathrm{C}$ stored in the Amazonian basin. Indeed, the carbon stored in the aboveground live biomass of intact Amazonian rainforests is estimated to be $93 \pm 23 \mathrm{PgC}$ (Malhi et al., 2006). Such large amounts of carbon may play a central role in the global carbon balance (Raymond, 2005), which raises the question of the magnitude of the carbon fluxes during podzol genesis and in response to drier periods that might occur in the future due to climate change. A schematic of the main carbon fluxes in Amazonian podzols (Leenheer, 1980; Lucas et al., 2012; Montes et al., 2011) is presented in Fig. 1. It should be noted that the organic matter $(\mathrm{OM})$ released by the topsoil horizons can be transferred downwards to the Bh horizons, but may also be rapidly transferred laterally to the river network via a perched water table on top of the Bh that circulates in the $\mathrm{E}$ horizon. The $\mathrm{OM}$ stored in the upper part of the $\mathrm{Bh}$ can also be remobilized and be transferred to the river network by the perched water table. Some of these fluxes have 


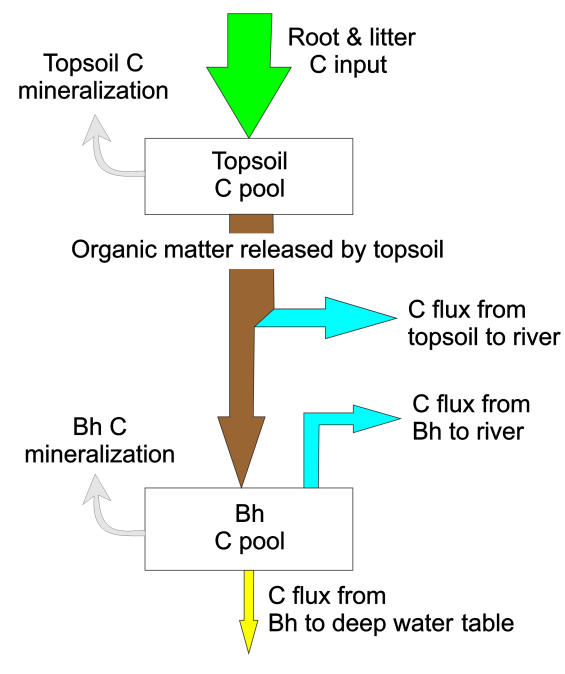

Figure 1. Schematic of the main $\mathrm{C}$ fluxes in a podzol.

been estimated in a small number of case studies or extrapolated from studies of the chemistry of large rivers (Tardy et al., 2009), but most of them remain unknown. Studies measuring carbon budgets at the profile scale or during soil profile genesis in temperate, boreal or tropical podzols are rare (Schaetzl and Rothstein, 2016; Van Hees et al., 2008). Schwartz (1988) studied giant podzol profiles in the Congo that began to form $40 \times 10^{3}$ years ago but where carbon accumulation in $\mathrm{Bh}$ was discontinuous because of a drier climate between 30 and $12 \mathrm{kyr} \mathrm{BP}$. The ${ }^{14} \mathrm{C}$ age of organic $\mathrm{C}$ from the $\mathrm{Bh}$ horizon of podzol profiles situated in the Manaus region (Brazil) was found to range from 1960 to 2810 years, and it was concluded that the podzols developed in less than $3 \times 10^{3}$ years (Horbe et al., 2004). As pointed out by Sierra et al. (2013), in order to corroborate this conclusion, it is necessary to produce a model that accounts for $\mathrm{C}$ additions and losses over time. Montes et al. (2011) roughly estimated the $\mathrm{C}$ flux to the $\mathrm{Bh}$ horizon to be $16.8 \mathrm{gC} \mathrm{m}^{-2}$ year $^{-1}$. Sierra et al. (2013) used a compartment model that was constrained by ${ }^{14} \mathrm{C}$ dating to estimate the carbon fluxes in a Colombian shallow podzol (Bh upper limit at $0.9 \mathrm{~m}$ ). They showed that the $\mathrm{C}$ fluxes from topsoil horizons to the Bh horizon were smaller $\left(2.1 \mathrm{gC} \mathrm{m}^{-2}\right.$ year $\left.^{-1}\right)$ than the fluxes estimated in Montes et al. (2011). However, they did not account for the age and genesis time of the Bh horizon.

In order to better understand the fluxes of $\mathrm{C}$ in Amazonian podzols and in particular to determine the rate of carbon accumulation in Bh horizons during podzol genesis, the size of the $\mathrm{C}$ fluxes to rivers via both the perched and deep water tables and the vulnerability of the podzol C stocks to potential changes in the moisture regime due to global climate change, four representative podzol profiles from the high Rio Negro basin were used to constrain a model of $\mathrm{C}$ fluxes. The high Rio Negro basin was chosen because it is a region that has the highest occurrence of podzol in the Amazon (Montes et al., 2011) (Fig. 2). The four representative profiles were selected from a database of 80 podzol profiles issued from 11 test areas which have been studied in detail and of which 11 have been dated; this database will be the subject of a further publication. The four profiles were used to constrain the simulations of $\mathrm{C}$ fluxes. We used a system dynamics modelling software package (Vensim) to simulate the formation of representative Amazonian podzol profiles by constraining both total carbon and radiocarbon with the data collected.

\section{Methods}

\subsection{Podzol profiles and carbon analysis}

Four podzol profiles were selected from our database as representative both from the point of view of the profile characteristics and the ${ }^{14} \mathrm{C}$ age of the $\mathrm{Bh}$ organic matter (Table 1 and Fig. 3). The MAR9 profile was developed on the Icá sedimentary formation, and has a waterlogged A horizon, a thin eluvial (E) horizon, a sandy-clay loam Bh with young organic matter $(\mathrm{OM})$ and a low $\mathrm{C}$ content; the DPQT profile was developed on a late Quaternary continental sediment younger than the Içá formation, and has an E horizon of intermediate thickness, a sandy Bh with young $\mathrm{OM}$ and a low C content; the UAU4 profile was developed on the Icá sedimentary formation, has a thick $\mathrm{E}$ horizon and a sandy $\mathrm{Bh}$ with old $\mathrm{OM}$, and the $\mathrm{C}$ content is high; the $\mathrm{P} 7 \mathrm{C}$ profile was developed on crystalline basement rock, and has a thick, waterlogged $\mathrm{O}$ horizon, an $\mathrm{E}$ horizon of intermediate thickness, a silt-loam Bh with old OM and a high C content. It should be noted that in the cases of the DPQT and UAU4 profiles, the lower limit of the $\mathrm{Bh}$ was not reached because the auger hole collapsed, meaning that for these profiles the Bh C stock is an underestimate.

Soil samples were analysed for $\mathrm{C}$ content with a TOCLCPN SSM-5000A, Total Organic Carbon Analyzer (Shimadzu). Radiocarbon measurements were carried out at the Poznań Radiocarbon Laboratory, Poland. We assumed that the proportion of bomb carbon in the Bh organic matter was negligible and calculated a conventional, uncalibrated age from the radiocarbon pMC (percent modern carbon) value. As the Bh organic matter is an open system mixing organic carbon of different ages, this age is an apparent age. Samples from the topsoil had a pMC higher than $100 \%$, which indicates that a significant part of the carbon in the topsoil is post-bomb and therefore should not be neglected. Assuming that the topsoil horizons reached a steady state before 1950 , we retrocalculated the pre- $1950 \mathrm{pMC}$ value of these samples using a dedicated model described in Sect. 2.2.

The data given in Table 1 were calculated by linear extrapolation of values measured on samples taken at different depths: between 11 and 28 samples per profile were used for the $C$ stocks' calculation and between 6 and 8 samples per profile were used for radiocarbon measurements. 
Table 1. The main characteristics of the podzol profiles used in the study. C stock and ages are given \pm error. $F_{a \text { t }}$ and $F_{a \mathrm{Bh}}:$ measured modern fraction of topsoil and $\mathrm{Bh}$ organic matter, respectively. Apparent ${ }^{14} \mathrm{C}$ ages of $\mathrm{OM}$ were calculated assuming Libby's half-life (after correction for bomb carbon for the topsoil horizons as explained hereafter).

\begin{tabular}{|c|c|c|c|c|}
\hline Profile identification & MAR9 & DPQT & UAU4 & P7C \\
\hline GPS coordinates & $\begin{array}{r}00^{\circ} 49^{\prime} 48.6^{\prime \prime} \mathrm{S} \\
67^{\circ} 24^{\prime} 25.1^{\prime \prime} \mathrm{W}\end{array}$ & $\begin{array}{l}00^{\circ} 15^{\prime} 24.0^{\prime \prime} \mathrm{N} \\
62^{\circ} 46^{\prime} 25.4^{\prime \prime} \mathrm{W}\end{array}$ & $\begin{array}{l}00^{\circ} 10^{\prime} 11.2^{\prime \prime} \mathrm{N} \\
67^{\circ} 48^{\prime} 56.3^{\prime \prime} \mathrm{W}\end{array}$ & $\begin{array}{r}00^{\circ} 36^{\prime} 42.6^{\prime \prime} \mathrm{S} \\
66^{\circ} 54^{\prime} 00.6^{\prime \prime} \mathrm{W}\end{array}$ \\
\hline Depth of the E-Bh transition (m) & 0.75 & 1.6 & 6.6 & 1.5 \\
\hline \multicolumn{5}{|l|}{ Topsoil horizons } \\
\hline $\begin{array}{l}\mathrm{C} \text { stock }\left(\mathrm{gC} \mathrm{m}^{-2}\right) \\
F_{a t} \\
\text { Apparent }{ }^{14} \mathrm{C} \text { age of } \mathrm{OM} \text { (year) }\end{array}$ & $\begin{array}{r}17722 \pm 886 \\
1.1124 \pm 0.0036 \\
62 \pm 25\end{array}$ & $\begin{array}{r}8056 \pm 403 \\
1.0797 \pm 0.0034 \\
108 \pm 27\end{array}$ & $\begin{array}{r}7519 \pm 376 \\
1.1094 \pm 0.0036 \\
65 \pm 25\end{array}$ & $\begin{array}{r}74129 \pm 3706 \\
1.0921 \pm 0.0035 \\
109 \pm 29\end{array}$ \\
\hline \multicolumn{5}{|l|}{ Bh horizons } \\
\hline $\begin{array}{l}\text { Texture } \\
\mathrm{C} \text { stock }\left(\mathrm{gC} \mathrm{m}^{-2}\right) \\
F_{a \mathrm{Bh}} \\
\text { Apparent }{ }^{14} \mathrm{C} \text { age of } \mathrm{OM} \text { (year) }\end{array}$ & $\begin{array}{r}\text { Sandy-clay loam } \\
55644 \pm 2782 \\
0.4315 \pm 0.0021 \\
6751 \pm 42\end{array}$ & $\begin{array}{r}\text { Sandy } \\
53180 \pm 2659 \\
0.3496 \pm 0.0016 \\
8442 \pm 37\end{array}$ & $\begin{array}{r}\text { Sandy } \\
107813 \pm 5391 \\
0.0557 \pm 0.0013 \\
23193 \pm 207\end{array}$ & $\begin{array}{r}\text { Silt loam } \\
158465 \pm 7923 \\
0.0440 \pm 0.0007 \\
25096 \pm 134\end{array}$ \\
\hline
\end{tabular}

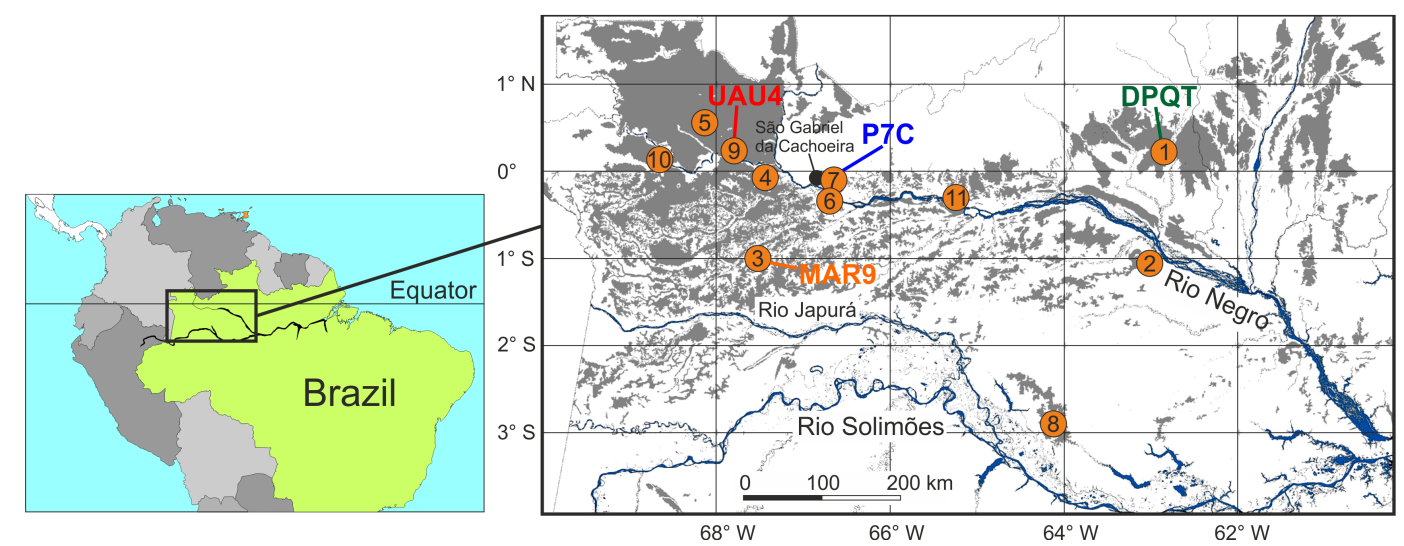

Figure 2. Location of the studied profiles. Grey areas in the detailed map indicate hydromorphic podzol areas. Orange spots identify test areas.

\subsection{Model design}

We used an approach comparable to previous studies which dealt with carbon budgets and radiocarbon data (e.g. Baisden et al., 2002; Menichetti et al., 2016; Sierra et al., 2013, 2014; Tipping et al., 2012). The model structure, based on the schematic shown in Fig. 1, and the names of compartments and rate constants are given in Fig. 4. As the turnover time of the $\mathrm{OM}$ in the topsoil horizons is short relative to the average $\mathrm{OM}$ turnover time in the $\mathrm{Bh}$, only one topsoil carbon pool was used, whereas two pools (fast and slow) were used to describe organic carbon dynamics in the Bh horizon. The $\mathrm{C}$ can leave the topsoil pool by mineralization, transfer to the $\mathrm{Bh}$ pools or via the river by the perched water table; it can leave the Bh pools by mineralization, transfer to the river by the perched water table or via the deep water table. We chose to neglect the flux of $\mathrm{C}$ from the fast $\mathrm{Bh}$ pool to the slow
Bh pool in order to facilitate the numerical resolution of the system comprising equations describing both the carbon and radiocarbon contents.

The equations describing changes in the carbon content of the different pools are presented below (see Fig. 4 to see the fluxes with which each rate constant is associated):

$$
\begin{aligned}
& \frac{\mathrm{d} C_{\mathrm{t}}}{\mathrm{d} t}=C_{\mathrm{I}}-\left(k_{\mathrm{t}}+\alpha_{\mathrm{t}-\mathrm{fBh}}+\alpha_{\mathrm{t}-\mathrm{sBh}}+\alpha_{\mathrm{t}-\mathrm{r}}\right) C_{\mathrm{t}}, \\
& \frac{\mathrm{d} C_{\mathrm{fBh}}}{\mathrm{d} t}=\alpha_{\mathrm{t}-\mathrm{fBh}} C_{\mathrm{t}}-\left(k_{\mathrm{fBh}}+\alpha_{\mathrm{fBh}-\mathrm{r}}+\alpha_{\mathrm{fBh}-\mathrm{d}}\right) C_{\mathrm{fBh}}, \\
& \frac{\mathrm{d} C_{\mathrm{sBh}}}{\mathrm{d} t}=\alpha_{\mathrm{t}-\mathrm{sBh}} C_{\mathrm{t}}-\left(k_{\mathrm{sBh}}+\alpha_{\mathrm{sBh}-\mathrm{r}}+\alpha_{\mathrm{sBh}-\mathrm{d}}\right) C_{\mathrm{sBh}},
\end{aligned}
$$

where $C_{\mathrm{I}}$ is the $\mathrm{C}$ input from litter and roots into the topsoil $\mathrm{C}$ pool; $C_{\mathrm{t}}$ the amount of $\mathrm{C}$ stored in the topsoil $\mathrm{C}$ pool; $C_{\mathrm{fBh}}$ and $C_{\mathrm{sBh}}$ the amount of $\mathrm{C}$ stored in the fast and slow $\mathrm{Bh}$ $\mathrm{C}$ pools, respectively; $k_{\mathrm{t}}, k_{\mathrm{fBh}}$ and $k_{\mathrm{sBh}}$ the $\mathrm{C}$ mineralization 


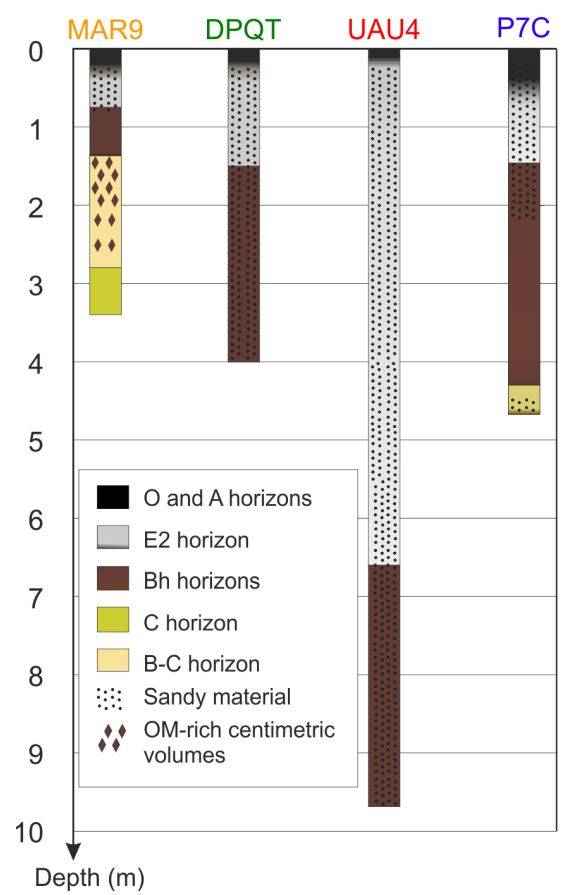

Figure 3. Sketch of the studied profiles.

rate constants in the topsoil, and the fast $\mathrm{Bh}$ and slow $\mathrm{Bh}$ $\mathrm{C}$ pools, respectively; $\alpha_{\mathrm{t}-\mathrm{fBh}}$ and $\alpha_{\mathrm{t}-\mathrm{sBh}}$ the transfer rates from the topsoil pool to the fast and slow Bh C pools, respectively; $\alpha_{\mathrm{t}-\mathrm{r}}, \alpha_{\mathrm{fBh}-\mathrm{r}}$ and $\alpha_{\mathrm{sBh}-\mathrm{r}}$ the transfer rates from, respectively, the topsoil and the fast $\mathrm{Bh}$ and slow $\mathrm{Bh}$ pools to the river by the perched water table; and $\alpha_{\mathrm{fBh}-\mathrm{d}}$ and $\alpha_{\mathrm{sBh}-\mathrm{d}}$ the transfer rates from the fast Bh and slow Bh pools to the deep water table, respectively.

The equations describing changes in the radiocarbon content of the different pools are the following:

$$
\begin{aligned}
& \frac{\mathrm{d} F_{a \mathrm{t}} C_{\mathrm{t}}}{\mathrm{d} t}=C_{\mathrm{I}} F_{a v}-\left(k_{\mathrm{t}}+\alpha_{\mathrm{t}-\mathrm{fBh}}+\alpha_{\mathrm{t}-\mathrm{sBh}}+\alpha_{\mathrm{t}-\mathrm{r}}\right) F_{a \mathrm{t}} C_{\mathrm{t}} \\
& \quad-\lambda F_{a \mathrm{t}} C_{\mathrm{t}}, \\
& \frac{\mathrm{d} F_{a \mathrm{fBh}} C_{\mathrm{fBh}}}{\mathrm{d} t}=\alpha_{\mathrm{t}-\mathrm{fBh}} F_{a \mathrm{t}} C_{\mathrm{t}}-\left(k_{\mathrm{fBh}}+\alpha_{\mathrm{fBh}-\mathrm{r}}\right. \\
& \left.\quad+\alpha_{\mathrm{fBh}-\mathrm{d}}\right) F_{a \mathrm{fBh}} C_{\mathrm{fBh}}-\lambda F_{a \mathrm{fBh}} C_{\mathrm{fBh}}, \\
& \frac{\mathrm{d} F_{a \mathrm{sBh}} C_{\mathrm{sBh}}}{\mathrm{d} t}=\alpha_{\mathrm{t}-\mathrm{sBh}} F_{a \mathrm{t}} C_{\mathrm{t}}-\left(k_{\mathrm{sBh}}+\alpha_{\mathrm{sBh}-\mathrm{r}}\right. \\
& \left.\quad+\alpha_{\mathrm{sBh}-\mathrm{d}}\right) F_{a \mathrm{sBh}} C_{\mathrm{sBh}}-\lambda F_{a \mathrm{sBh}} C_{\mathrm{sBh}},
\end{aligned}
$$

where $\lambda$ is the ${ }^{14} \mathrm{C}$ radioactive decay constant, $F_{a v}$ the radiocarbon fraction in the organic matter entering the topsoil $\mathrm{C}$ pool and $F_{a i}$ the radiocarbon fraction in each pool $i$, the radiocarbon fractions being expressed as absolute modern fraction, i.e. the ${ }^{14} \mathrm{C} /{ }^{12} \mathrm{C}$ ratio of the sample normalized for ${ }^{13} \mathrm{C}$ fractionation to the oxalic acid standard ${ }^{14} \mathrm{C} /{ }^{12} \mathrm{C}$ normalized for ${ }^{13} \mathrm{C}$ fractionation and for radio decay at the year of measurement (Stuiver and Polach, 1977).

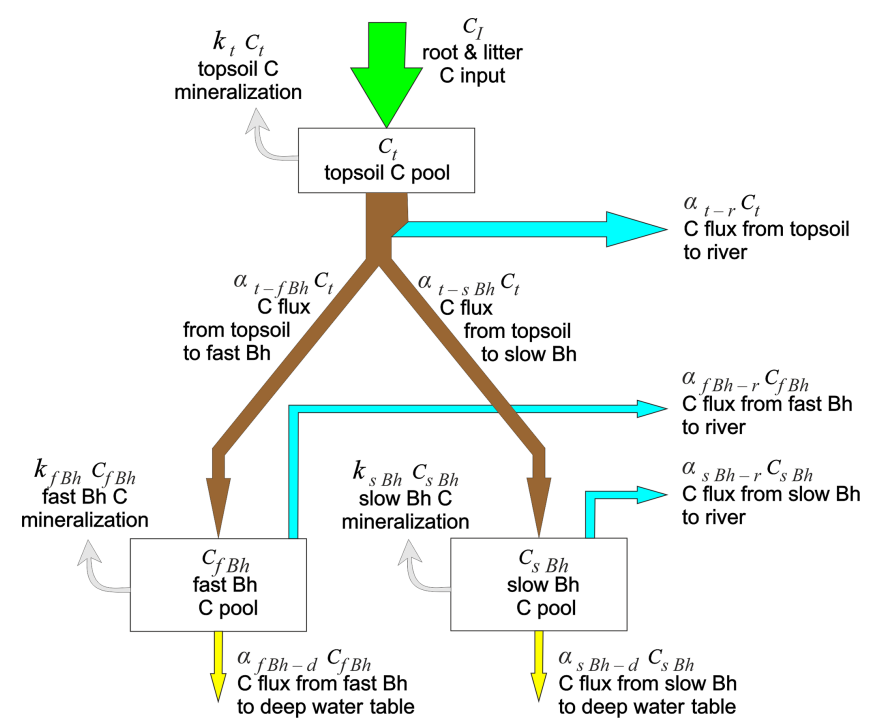

Figure 4. Model design.

With regard to the apparent age of the topsoil organic matter enriched in post-bomb carbon, we considered a single pool that reached a steady state before 1955 (Fig. 5), which allowed the retrocalculation of the radiocarbon fraction $F_{a t}$ in 1955 based on the following equation:

$$
\begin{aligned}
& C_{\mathrm{t}} F_{a \mathrm{t}_{i+1}}=C_{\mathrm{t}} F_{a \mathrm{t}_{i}}-\lambda C_{\mathrm{t}} F_{a \mathrm{t}_{i}}+\left(F_{a v_{i}}-F_{a \mathrm{t}_{i}}\right) C_{\mathrm{I}} \Leftrightarrow F_{a \mathrm{t}_{i}} \\
& \quad=\frac{C_{\mathrm{t}} F_{a \mathrm{t}_{i+1}}-C_{\mathrm{I}} F_{a v_{i}}}{C_{\mathrm{t}}-\lambda C_{\mathrm{t}}+C_{\mathrm{I}}},
\end{aligned}
$$

where $F_{a t_{i}}$ and $F_{a t_{i+1}}$ are the radiocarbon fractions of the topsoil C pool in years $i$ and $i+1$, respectively, and $F_{a v_{i}}$ the radiocarbon fraction in the organic matter entering the topsoil $\mathrm{C}$ pool in year $i$. Starting from the $F_{a t_{2015}}$ value (value at the year of measurement), the $F_{a t_{1955}}$ value (pre-bomb value) is calculated by successive iterations, giving an expression as a function of $C_{\mathrm{I}}$, which is then computed by approximation to satisfy the steady-state condition. We used the tropospheric $\mathrm{D}^{14} \mathrm{CO}_{2}$ record from 1955 to 2011 at Wellington (NIWA, 2016) to estimate the annual value of $F_{a v_{i}}$.

An underlying assumption of this work is that soil formation processes remained constant over time. An alternative assumption might be, for example, that all the Bh organic matter had accumulated in a very short time, after which the Bh was no longer subjected to external exchanges. This scenario could also produce profile ages close to the observed ${ }^{14} \mathrm{C}$ profile ages. Such a case, however, is unlikely. The climate of the high Rio Negro region is likely to have remained humid and forested since the Pliocene, although less humid episodes may have occurred during the Holocene glacial episodes (Colinvaux and De Oliveira, 2001; Van der Hammen and Hooghiemstra, 2000). It is also possible that the rate at which soil formation proceeded decelerated over time. This will be commented on below. 


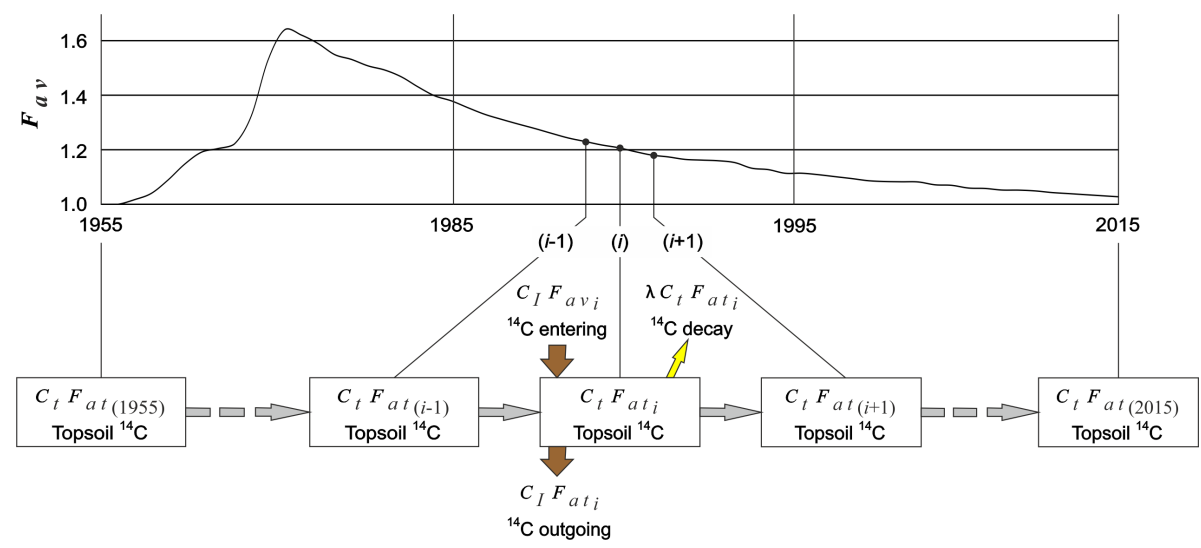

Figure 5. Evolution of the ${ }^{14} \mathrm{C}$ pool in a topsoil that reached a steady state before 1955 .

\subsection{Model running and tuning}

We used the Vensim ${ }^{\circledR}$ Pro (Ventana Systems inc.) dynamic modelling software to simulate the $\mathrm{C}$ dynamics. After setting the initial values for $\mathrm{C}$ pools, the model was run in the optimize mode, leaving the model to adjust the rate constants in order to minimize the difference between simulated and measured $\mathrm{C}$ pool values and ages. However, frequently the model did not converge when run in this way. We found that it was because of the great difference between the convergence times between the topsoil $\mathrm{C}$ pool and the slow Bh $\mathrm{C}$ pool. The long times required to model the genesis of the Bh horizons resulted in numerical errors when modelling the topsoil behaviour, because the values of exponential exponents exceeded the maximum values that the computer could handle (see for example Eq. 12 below). To circumvent this technical problem, we optimized the model separately for the topsoils and for the Bh horizons, and we found that at the timescale of the formation of $\mathrm{Bh}$, the topsoil $\mathrm{C}$ pool and the topsoil $\mathrm{C}$ fluxes to river and $\mathrm{Bh}$ horizons could be considered constant.

Although the model structure in Fig. 4 contains two C pools in the Bh horizon, we calculated the numerical solutions of equations considering both carbon budget and radiocarbon age for a single-pool $\mathrm{Bh}$ in order to determine whether the model could be simplified. Furthermore, this approach allowed us to better assess the weight of the different rate constants in the long-term behaviour of a given pool. The calculation in the simplified configuration is shown in Fig. 6.

In this configuration, the carbon content of the pool is given by

$\frac{\mathrm{d} C_{\mathrm{Bh}}}{\mathrm{d} t}=\alpha_{\mathrm{t}-\mathrm{Bh}} C_{\mathrm{t}}-\beta_{\mathrm{Bh}} C_{\mathrm{Bh}}$,

where $C_{\mathrm{t}}$ is the amount of $\mathrm{C}$ stored in the topsoil pool, $\alpha_{\mathrm{t}-\mathrm{sBh}}$ the transfer rates from the topsoil pool to the $\mathrm{Bh}$ pool, $C_{\mathrm{Bh}}$ the amount of $\mathrm{C}$ stored in the $\mathrm{Bh}$ pool and $\beta_{\mathrm{Bh}}$ the transfer rate of $\mathrm{C}$ leaving the $\mathrm{Bh}$ pool. The solution of this equation

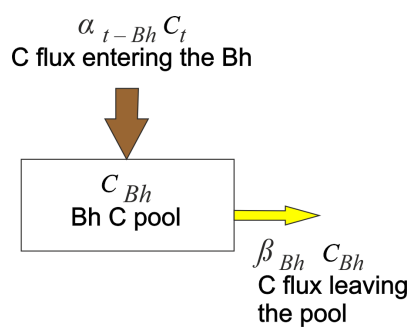

Figure 6. Simplified design for one pool.

with the initial condition $C_{\mathrm{Bh}}=C_{0 \mathrm{Bh}}$ when $t=0$ is

$C_{\mathrm{Bh}}=\frac{\alpha_{t-\mathrm{Bh}} C_{\mathrm{t}}}{\beta_{\mathrm{Bh}}}+\left(C_{0 \mathrm{Bh}}-\frac{\alpha_{\mathrm{t}-\mathrm{Bh}} C_{\mathrm{t}}}{\beta_{\mathrm{Bh}}}\right) e^{-\beta_{\mathrm{Bh}} t}$.

The equation related to radiocarbon content is the following:

$\frac{\mathrm{d} F_{a \mathrm{Bh}} C_{\mathrm{Bh}}}{\mathrm{d} t}=\alpha_{\mathrm{t}-\mathrm{Bh}} C_{\mathrm{t}} F_{a \mathrm{t}}-\left(\beta_{\mathrm{Bh}}+\lambda\right) F_{a \mathrm{Bh}} C_{\mathrm{Bh}}$,

where $F_{a \mathrm{Bh}}$ is the radiocarbon fraction in the $\mathrm{Bh}$.

Considering that the $\mathrm{C}$ input from the topsoil to the $\mathrm{Bh}$ and its radiocarbon fraction are constant with time, it comes from the two previous equations:

$\frac{\mathrm{d} F_{a \mathrm{Bh}}}{\mathrm{d} t}=$

$\frac{\beta_{\mathrm{Bh}} \alpha_{\mathrm{t}-\mathrm{Bh}} C_{\mathrm{t}} F_{a \mathrm{t}}-F_{a \mathrm{Bh}}\left(\beta_{\mathrm{Bh}} \alpha_{\mathrm{t}-\mathrm{Bh}} C_{\mathrm{t}}+\lambda\left(\alpha_{t-\mathrm{Bh}} C_{\mathrm{t}}-\left(\alpha_{\mathrm{t}-\mathrm{Bh}} C_{\mathrm{t}}-\beta_{\mathrm{Bh}} C_{0 \mathrm{Bh}}\right) e^{-\beta_{\mathrm{Bh}} t}\right)\right)}{\alpha_{\mathrm{t}-\mathrm{Bh}} C_{\mathrm{t}}-\left(\alpha_{\mathrm{t}-\mathrm{Bh}} C_{\mathrm{t}}-\beta_{\mathrm{Bh}} C_{0 \mathrm{Bh}}\right) e^{-\beta_{\mathrm{Bh}} t}}$

The analytical solution of this equation with the initial condition $F_{a \mathrm{Bh}}=F_{a \mathrm{t}}$ when $t=0$ is

$$
\begin{aligned}
& F_{a \mathrm{Bh}}= \\
& \frac{\beta_{\mathrm{Bh}} F_{a \mathrm{t}} e^{-\lambda t}\left(\beta_{\mathrm{Bh}} C_{0 \mathrm{Bh}}+\alpha_{\mathrm{t}-\mathrm{Bh}} C_{\mathrm{t}}\left(e^{\left(\beta_{\mathrm{Bh}}+\lambda\right) t}-1\right)+\lambda C_{0 \mathrm{Bh}}\right)}{\left(\beta_{\mathrm{Bh}}+\lambda\right)\left(\beta_{\mathrm{Bh}} C_{0 \mathrm{Bh}}+\alpha_{\mathrm{t}-\mathrm{Bh}} C_{\mathrm{t}}\left(e^{\beta_{\mathrm{Bh}} t}-1\right)\right)} .
\end{aligned}
$$




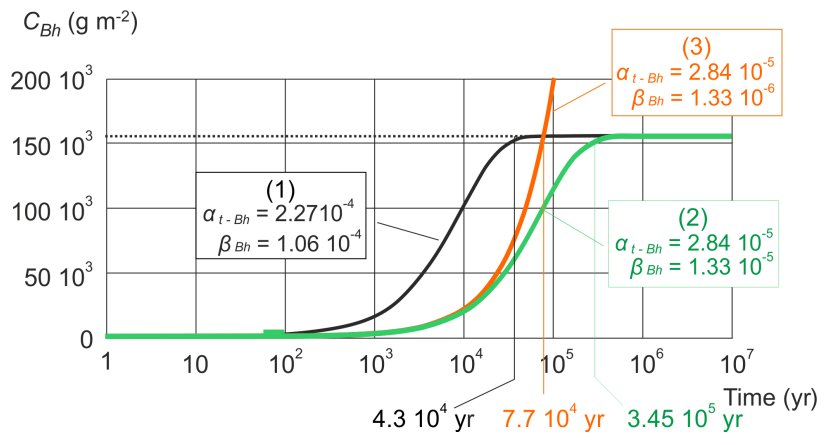

Figure 7. Single-pool modelling of $C_{\mathrm{Bh}}$ of the $\mathrm{P} 7 \mathrm{C}$ profile; $C_{0 \mathrm{Bh}}$ set to 0 .

\section{Results and discussion}

\subsection{Modelling the formation of a single-pool $\mathrm{Bh}$}

This section presents conceptual results on the basis of the simplified diagram given in Fig. 6 and in which the flux leaving the $\mathrm{Bh}$ is described by a single rate $\beta_{\mathrm{Bh}}$. This single rate represents loss from the pool through the mineralization of organic carbon, through lateral flow in the perched water table to the river, and through percolation of dissolved organic carbon (DOC) to the deep water table.

\subsubsection{Obtaining the carbon stock}

Unsurprisingly, the greater the difference between input and output $\mathrm{C}$ fluxes, the faster a given $C_{\mathrm{Bh}}$ stock is reached. With a constant input flux and a constant output rate, the output flux progressively increases with time because $C_{\mathrm{Bh}}$ increases, until the input and output fluxes become equal, after which the $C_{\mathrm{Bh}}$ reaches a steady state.

When the model is constrained only by the measured values of $\mathrm{C}$ stocks, a number of solutions are possible (Fig. 7). The example given in Fig. 7 is based on data from the P7C profile (Table 1). Curves 1 and 2 describe the evolution of $C_{\mathrm{Bh}}$ with time when the $\beta_{\mathrm{Bh}}$ rate is constrained to reach a steady state for the currently observed $\mathrm{C}$ stock (158465 $\left.\mathrm{gC} \mathrm{m}^{-2}\right)$. The input flux was set at 2.1 and $16.8 \mathrm{~g} \mathrm{~m}^{-2}$ year $^{-1}$ for curves 1 and 2 , respectively, values proposed by Montes et al. (2011) and Sierra et al. (2013), respectively. The resulting constrained values of $\alpha_{\mathrm{t}}$ - Bh and $\beta_{\mathrm{Bh}}$ rates are given in the figure. The times required to reach $99 \%$ of the steady-state values are $43 \times 10^{3}$ and $345 \times 10^{3}$ years for curves 1 and 2, respectively. We used here and thereafter an arbitrary $99 \%$ threshold because, as shown in Fig. 8, this value gives a result sufficiently close to the horizontal asymptote to give a reasonable evaluation of the time necessary to reach a steady state.

The currently observed $\mathrm{C}$ stock can be reached in a shorter time, however, if for a given input flux the value of $\beta_{\mathrm{Bh}}$ is reduced below the value needed to obtain the currently

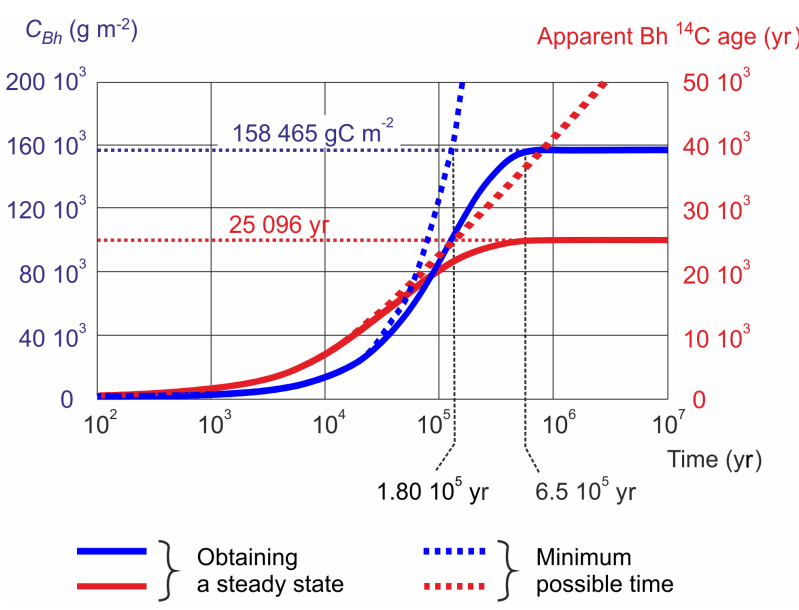

Figure 8. Single-pool modelling of both $C_{\mathrm{Bh}}$ and $\mathrm{Bh}{ }^{14} \mathrm{C}$ age of the $\mathrm{P} 7 \mathrm{C}$ profile. Corresponding values of $\mathrm{C}$ input fluxes and $\beta_{\mathrm{Bh}}$ rates are given in Table 2.

observed $\mathrm{C}$ stock at a steady state. An example is given by curve 3 : the input flux is set at $2.1 \mathrm{~g} \mathrm{~m}^{-2}$ year ${ }^{-1}$, as for curve 1 , but the $\beta_{\mathrm{Bh}}$ rate is reduced by 1 order of magnitude. In such a case, it would require $78 \times 10^{3}$ years to obtain the currently observed $\mathrm{C}$ stock. A value of $\beta_{\mathrm{Bh}}$ set to 0 gives the minimum time required to obtain the carbon stock $\left(50 \times 10^{3}\right.$ years if the input flux is set to $2.1 \mathrm{~g} \mathrm{~m}^{-2}$ year $\left.^{-1}\right)$.

\subsubsection{Obtaining both carbon stock and ${ }^{14} \mathrm{C}$ age}

When the model was constrained by both carbon stock and ${ }^{14} \mathrm{C}$ age, then a unique solution for reaching the steady state was obtained. This is shown for the P7C profile in Fig. 8 (solid lines), where $99 \%$ of the measured values of $C_{\mathrm{Bh}}$ and apparent ${ }^{14} \mathrm{C}$ age $\left(158465 \mathrm{gC} \mathrm{m}^{-2}\right.$ and 25096 years, respectively) were obtained in approximately $590 \times 10^{3}$ years; carbon input fluxes to the $\mathrm{Bh}$ and $\beta_{\mathrm{Bh}}$ rate were constrained to very low values, $0.95 \mathrm{~g} \mathrm{~m}^{2}$ year ${ }^{1}$ and $5.9 \times 10^{-6}$ year $^{-1}$, respectively. Note that for higher values of the $\beta_{\mathrm{Bh}}$ rate, there was no solution because the ${ }^{14} \mathrm{C}$ age could never be reached.

The simulation of the minimum time required for the observed carbon stock and ${ }^{14} \mathrm{C}$ age to be reached is also shown in Fig. 8 (dashed lines). This simulation was obtained by adjusting the input rate with an output flux close to 0 , but different from zero for numerical reasons. We used $\beta_{\mathrm{Bh}}=10^{-10}$ after checking that the difference between the minimum time obtained using $\beta_{\mathrm{Bh}}=10^{-10}$ and $\beta_{\mathrm{Bh}}=10^{-20}$ was negligible (lower than $0.0005 \%$ ).

The minimum time required for the $\mathrm{C}$ stock and ${ }^{14} \mathrm{C}$ age to be reached and the time required to reach $99 \%$ of the $\mathrm{C}$ stock and ${ }^{14} \mathrm{C}$ age at a steady state are given, along with the associated $\mathrm{C}$ input fluxes and $\beta_{\mathrm{Bh}}$ rates, in Table 2 for each of the studied profiles. Under each of the conditions, the time required is an exponential function of the apparent ${ }^{14} \mathrm{C}$ age of the Bh (Fig. 9). 
Table 2. Results of simulation for a single-pool Bh: minimum genesis time and time to steady state.

\begin{tabular}{|c|c|c|c|c|}
\hline & MAR9 & DPQT & UAU4 & P7C \\
\hline $\mathrm{Bh}$ apparent ${ }^{14} \mathrm{C}$ age (year) & 6751 & 8442 & 23193 & 25096 \\
\hline Corresponding $F_{a \mathrm{Bh}}$ value & 0.4315 & 0.3496 & 0.0557 & 0.0440 \\
\hline$C_{\mathrm{t}}\left(\mathrm{gC} \mathrm{m}^{-2}\right)$ & 17722 & 8056 & 7519 & 74129 \\
\hline$F_{a t}$ value of the $\mathrm{C}$ input & 0.9923 & 0.9866 & 0.9919 & 0.9865 \\
\hline \multicolumn{5}{|c|}{ Minimum time required for obtaining $\mathrm{C}$ stock and ${ }^{14} \mathrm{C}$ age $\left(\beta_{\mathrm{Bh}}=10^{-10}\right)$} \\
\hline Time (year) & 15929 & 21011 & 143000 & 180100 \\
\hline$\alpha_{\mathrm{t}-\mathrm{Bh}}$ rate $\left(\right.$ year $\left.^{-1}\right)$ & $1.97 \times 10^{-4}$ & $3.14 \times 10^{-4}$ & $1.00 \times 10^{-4}$ & $1.19 \times 10^{-5}$ \\
\hline Input $\mathrm{C}$ flux $\left(\mathrm{gC} \mathrm{m}^{-2}\right.$ year $\left.^{-1}\right)$ & 3.49 & 2.53 & 0.75 & 0.88 \\
\hline \multicolumn{5}{|c|}{ Time required to reach $99 \%$ of the steady-state value } \\
\hline Time (year) & 48000 & 66700 & 489000 & 650000 \\
\hline$\alpha_{\mathrm{t}-\mathrm{Bh}}$ rate $\left(\right.$ year $\left.^{-1}\right)$ & $9.63 \times 10^{-5}$ & $4.51 \times 10^{-4}$ & $1.06 \times 10^{-4}$ & $1.24 \times 10^{-5}$ \\
\hline Input $\mathrm{C}$ flux $\left(\mathrm{gC} \mathrm{m}^{-2}\right.$ year $\left.^{-1}\right)$ & 5.36 & 3.63 & 0.80 & 0.92 \\
\hline$\beta_{\mathrm{Bh}}$ rate $\left(\right.$ year $\left.^{-1}\right)$ & $9.56 \times 10^{-5}$ & $6.83 \times 10^{-5}$ & $7.41 \times 10^{-6}$ & $5.81 \times 10^{-6}$ \\
\hline Mean residence time at steady state (year) & 10381 & 14451 & 128349 & 166805 \\
\hline
\end{tabular}

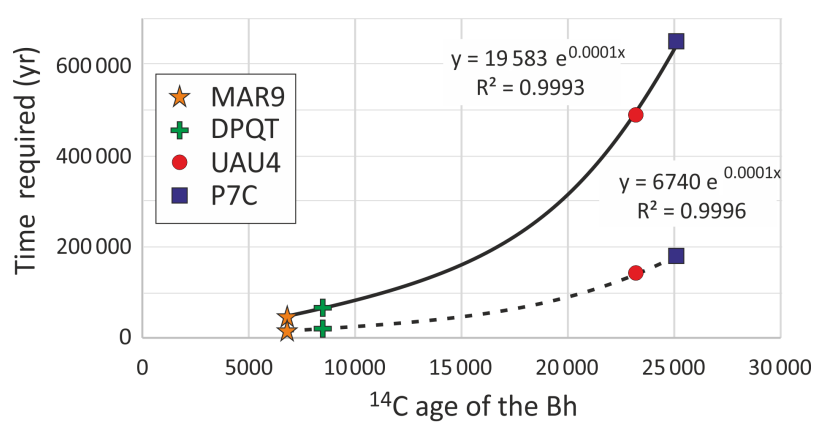

- Time required to reach $99 \%$ of the steady-state value -.. - Absolute minimum time

Figure 9. Relationship between the ${ }^{14} \mathrm{C}$ age of the $\mathrm{Bh}$ and the time needed to form the Bh (single-pool modelling).

Taking into account the maximum absolute error does not significantly change the simulation results: the maximum absolute error in the genesis times is lower than 1.0, 0.9, 3.5 and $2.9 \%$ for MAR9, DPQT, UAU4 and P7C, respectively. Since such percentages do not alter the orders of magnitude and trends discussed below, the error will not be considered in the following.

The time taken for the $\mathrm{Bh}$ horizon of a given profile to form is likely between the two values shown in Table 2 and Fig. 9. The minimum time required for obtaining $\mathrm{C}$ stock and ${ }^{14} \mathrm{C}$ age is an absolute minimum which assumes that the $\mathrm{C}$ output from the Bh was zero, which is not likely. On the other hand, there is no evidence that a steady state has been reached, especially in the case of the two youngest profiles (MAR9 and DPQT). Consequently, the time taken for the formation of the $\mathrm{Bh}$ horizons is very likely comprised between $15 \times 10^{3}$ and $65 \times 10^{3}$ years for the two youngest pro- files and between $140 \times 10^{3}$ and $600 \times 10^{3}$ years for the two oldest, durations compatible with rough estimates given in Du Gardin (2015). These results also show that the input C fluxes to the $\mathrm{Bh}$ and correspondingly the output $\mathrm{C}$ fluxes are 3 to 5 times higher for younger than for older profiles and that the older profiles would have an output rate of 1 order of magnitude lower than the younger profiles. It is not immediately clear why such large differences would exist. Previous studies have shown (1) that a part of the accumulated Bh OM is remobilized and exported towards the river network (Bardy et al., 2011); and (2) that the water percolating from the $\mathrm{Bh}$ to deeper horizon OM contains significant amounts of DOC, even in older profiles (around $2 \mathrm{mg} \mathrm{L}^{-1}$, Lucas et al., 2012). These observations are not consistent with the obtained very low $\beta_{\mathrm{Bh}}$ rates, which give input and output $\mathrm{C}$ fluxes lower than $1 \mathrm{gC} \mathrm{m}^{2}$ year $^{-1}$ for profiles UAU4 and P7C. This suggests that a single $\mathrm{Bh} \mathrm{C}$ pool is incorrect and that two pools of $\mathrm{Bh} \mathrm{C}$ are required to adequately represent $\mathrm{Bh} \mathrm{C}$ dynamics.

\subsection{Modelling the formation of the whole profile with a two-pool Bh}

\subsubsection{Topsoil horizons}

As explained in Sect. 2.3, the topsoil horizons were modelled separately because the time needed to reach a steady state is very much shorter for the topsoil horizons than for the $\mathrm{Bh}$ horizons. The steady-state condition was given by $\beta_{t}=C_{\mathrm{I}} C_{\mathrm{t}}^{-1}$. Observations data were $C_{\mathrm{t}}, F_{a v}, F_{a \mathrm{t}}$ and $k_{\mathrm{t}}$. The $k_{\mathrm{t}}$ mineralization rate was set to $2.57 \times 10^{-3}$ year $^{-1}$, following preliminary mineralization experiments (unpublished data). The optimizing parameter was $\beta_{\mathrm{t}}$ and a multiple cost function minimized the differences between modelled and 
Table 3. Modelling the topsoil horizons. $C_{\mathrm{t}}$ : topsoil C stock; $C_{\mathrm{I}}$ : C input flux from roots and litter; time to steady state: time required to reach $99 \%$ of the steady-state values for $C_{\mathrm{t}}$ and ${ }^{14} \mathrm{C}$ age; $\beta_{\mathrm{t}}$ : sum of the output rates $\left(\beta_{\mathrm{t}}=k_{\mathrm{t}}+\alpha_{\mathrm{t}-\mathrm{r}}+\alpha_{\mathrm{t}}-f_{\mathrm{Bh}}+\alpha_{\mathrm{t}}\right)$.

\begin{tabular}{|c|c|c|c|c|}
\hline & MAR 9 & DPQT & UAU4 & P7C \\
\hline$C_{\mathrm{t}}\left(\mathrm{g} \mathrm{m}^{-2}\right)$ & 17722 & 8056 & 7519 & 74129 \\
\hline Apparent ${ }^{14} \mathrm{C}$ age (year) & 62 & 108 & 65 & 109 \\
\hline$F_{a \text { t }}$ value & 0.9923 & 0.9866 & 0.9919 & 0.9865 \\
\hline$C_{\mathrm{I}}\left(\mathrm{g} \mathrm{m}^{-2}\right.$ year $\left.^{-2}\right)$ & 286 & 74 & 116 & 676 \\
\hline Time to steady state (year) & 399 & 696 & 420 & 705 \\
\hline$\beta_{\mathrm{t}}\left(\right.$ year $\left.^{-1}\right)$ & $1.61 \times 10^{-2}$ & $9.23 \times 10^{-3}$ & $1.54 \times 10^{-2}$ & $9.12 \times 10^{-3}$ \\
\hline
\end{tabular}
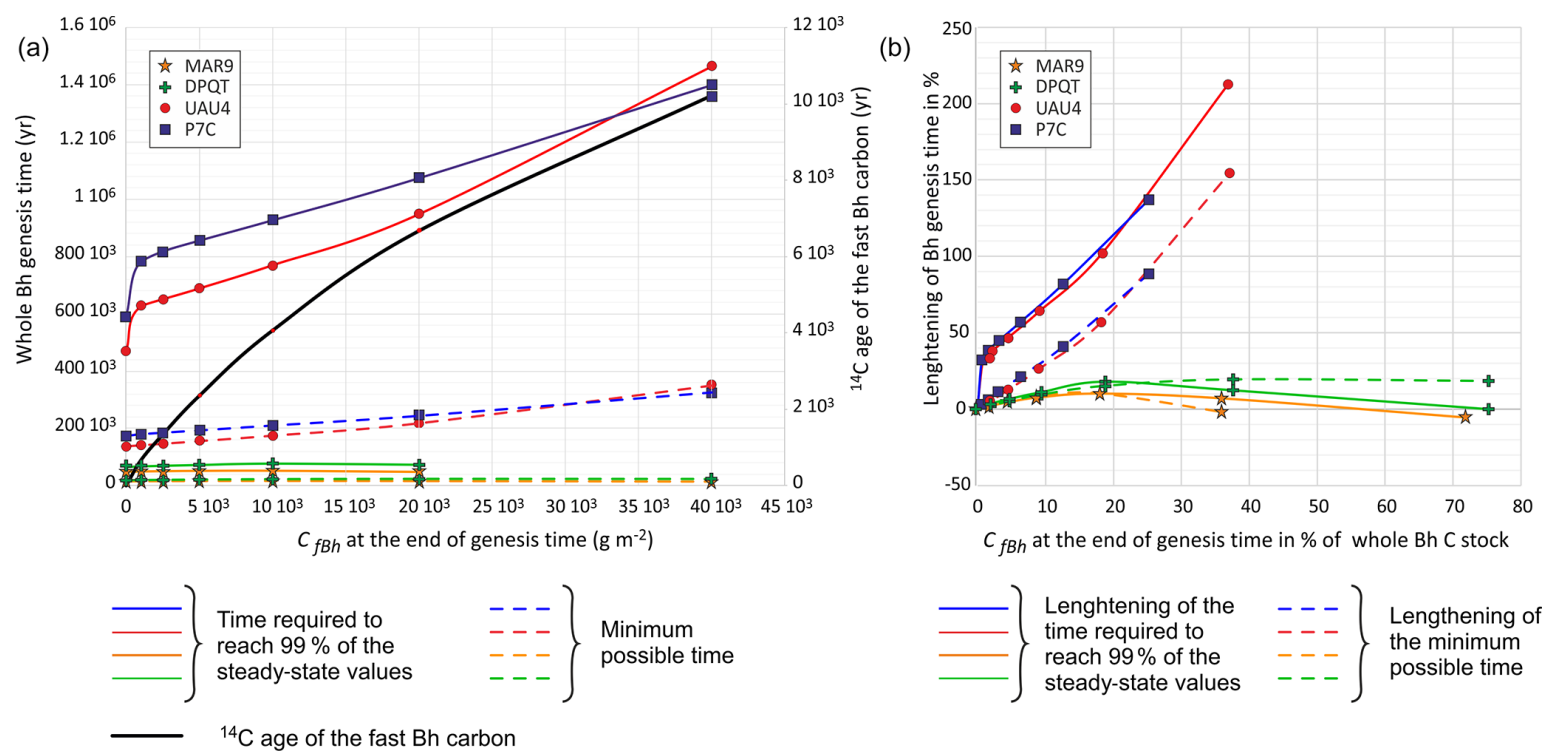

Figure 10. Effect of the fast $\mathrm{Bh}$ pool size on the whole $\mathrm{Bh}$ genesis time and the ${ }^{14} \mathrm{C}$ age of the fast Bh. (a) Absolute values; (b) values expressed in $\%$.

observed values for $C_{\mathrm{t}}$ and $F_{a \mathrm{t}}$. The model outputs for the topsoil horizons of the studied profiles are given in Table 3.

The results suggest that the topsoil OM in the four profiles needed only between 400 and 700 years to reach a steady state, if the present-day topsoils are indeed in a steady state. The total $\mathrm{C}$ flux through the topsoil $\left(C_{\mathrm{I}}\right)$ is high for the MAR9 profile $\left(286 \mathrm{~g} \mathrm{~m}^{-2}\right.$ year $\left.^{-1}\right)$ and very high for the P7C profile $\left(676 \mathrm{~g} \mathrm{~m}^{-2}\right.$ year $\left.^{-1}\right)$, in accordance with their high topsoil C stock (17 722 and $74129 \mathrm{~g} \mathrm{~m}^{-2}$, respectively) and the very young age of their organic matter. Note that the topsoil OM ages are younger than ages reported by Trumbore (2000) for boreal, temperate or tropical forests. Differences between modelled fluxes through the topsoil are consistent with the field observations: the lowest fluxes (UAU4 and DPQT) correspond to well-drained topsoil horizons, with a relatively thin type Mor A horizon, when the highest fluxes (P7C) correspond to a podzol having a thick O horizon in a very hydromorphic area. The MAR9 profile is intermediate. It should be noted that the flux through the P7C topsoil would be more than 1.5 times higher than the commonly ac- cepted value for the $\mathrm{C}$ annually recycled by the aboveground litter in equatorial forests (around $425 \mathrm{gC} \mathrm{m}^{-2}$ year $^{-1}$ - Wanner, 1970; Cornu et al., 1997; Proctor, 2013), indicating a strong contribution of the belowground litter (root litter).

\subsubsection{Bh horizons}

The partitioning of the $\mathrm{C}$ flux leaving the topsoil between the river (rate $\alpha_{\mathrm{t}-\mathrm{r}}$ ), the fast pool of the Bh (rate $\alpha_{\mathrm{t}-\mathrm{fBh}}$ ) and the slow pool of the $\mathrm{Bh}\left(\right.$ rate $\left.\alpha_{\mathrm{t}-\mathrm{sBh}}\right)$ is unknown. This is also the case for the partitioning of the $\mathrm{C}$ flux from the $\mathrm{Bh}$ pools between the river (rates $\alpha_{\mathrm{fBh}-\mathrm{r}}$ and $\alpha_{\mathrm{sBh}-\mathrm{r}}$ ) and the deep horizons (rates $\alpha_{\mathrm{fBh}-\mathrm{d}}$ and $\alpha_{\mathrm{sBh}-\mathrm{d}}$ ). Consequently, the system is not sufficiently constrained with the ${ }^{14} \mathrm{C}$ age of the bulk Bh and there is an infinity of solutions for modelling the Bh formation.

We therefore carried out a sensitivity analysis to determine how the main parameters (size of the fast pool of the Bh, $\mathrm{C}$ flux input and output $\mathrm{C}$ rates for the Bh pools) affected the profile genesis time and to understand the relationships between these parameters. 

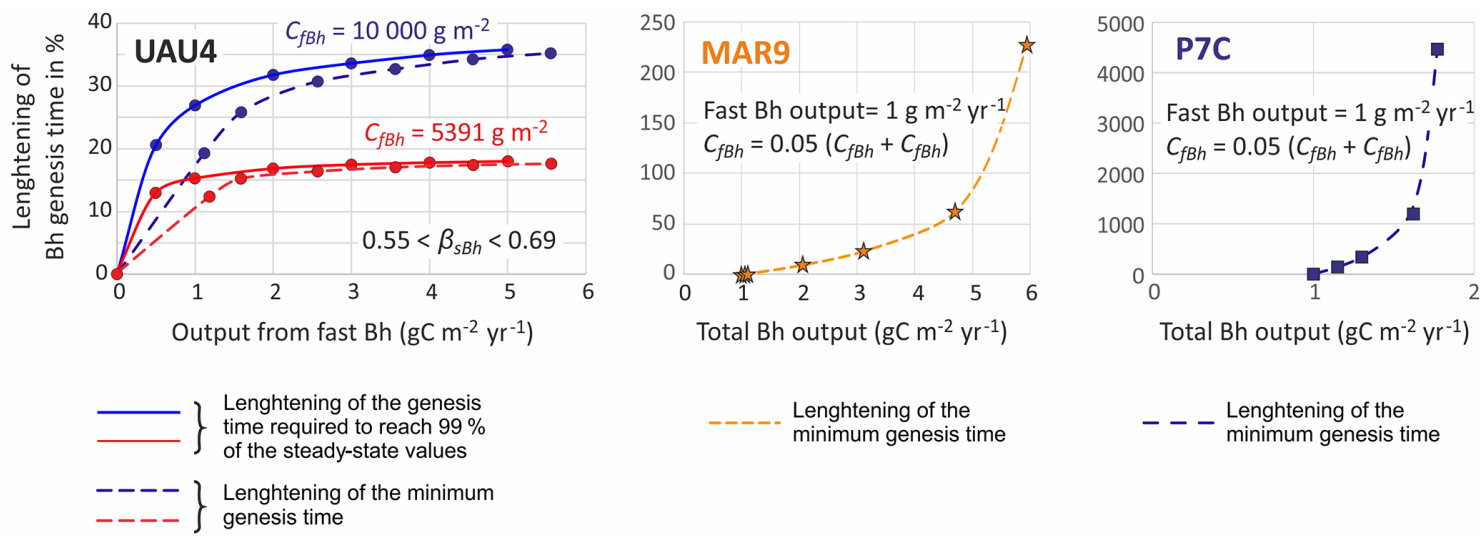

Figure 11. Effect of constraining the output $\mathrm{C}$ fluxes from the Bh on the genesis time. UAU4: effect of the fast Bh output flux. MAR9 and P7C: effect of the slow Bh output flux.

Sensitivity to the size of the fast Bh pool: Fig. 10 shows simulation results with an output $\mathrm{C}$ flux from $\mathrm{Bh}$ set to be $2 \mathrm{~g} \mathrm{~m}^{-2}$ year $^{-1}$ at the end of the genesis time and with values for $C_{\mathrm{fBh}}$ ranging from $2.5 \times 10^{3}$ to $40 \times 10^{3} \mathrm{~g} \mathrm{~m}^{-2}$, through $5 \times 10^{3}, 10 \times 10^{3}$ and $20 \times 10^{3}$. In most configurations, the presence of a fast pool in the Bh extends the time taken for the whole $\mathrm{Bh}$ genesis relative to a single-pool $\mathrm{Bh}$. This lengthening of the genesis time increases as a function of the ${ }^{14} \mathrm{C}$ age of the whole $\mathrm{Bh}$ and as a function of the size of the fast $\mathrm{Bh}$ pool $\left(C_{\mathrm{fBh}}\right)$. A size of the fast Bh pool set to $5 \%$ of the whole Bh stock would give a low estimate of the Bh genesis time.

Sensitivity to the $C$ fluxes leaving the Bh pools: the genesis time of the profile lengthens with increasing $C$ flux from the bulk Bh. The lengthening of the genesis depends, however, on how the $\mathrm{C}$ fluxes leaving the $\mathrm{Bh} \mathrm{C}$ pools vary and on the source of the variation (Fig. 11). In the situation where there is a progressive increase in the $\mathrm{Bh}$ output beginning from 0 , and this increase is due to the fast $\mathrm{Bh}$ pool, the lengthening of the genesis time is fast at first and then slows. An example is given in Fig. 11 for the UAU4 profile for two values of $C_{\mathrm{fBh}}$. When the increase is due to the slow Bh pool, the lengthening of the genesis time is slow at first and then becomes very high. An example is given in Fig. 11 for the MAR9 and P7C profiles, respectively.

The conclusion of this sensitivity study is that, when the size of the fast $\mathrm{Bh}$ pool or the $\mathrm{C}$ output fluxes from the $\mathrm{Bh}$ pools begins to grow from zero, the genesis time of the profiles increases rapidly by a factor of 5 to $20 \%$ for the two youngest profiles and 15 to more than $60 \%$ for the two oldest profiles.

Modelling the formation of the whole profiles: observation data were $C_{\mathrm{Bh}}$ (sum of $C_{\mathrm{fBh}}$ and $\left.C_{\mathrm{sBh}}\right), F_{a \mathrm{t}}, F_{a \mathrm{Bh}}\left(F_{a}\right.$ value of the bulk Bh), $\alpha_{\mathrm{t}-\mathrm{fBh}}, k_{\mathrm{fBh}}, k_{\mathrm{sBh}}, \alpha_{\mathrm{fBh}-\mathrm{d}}$, and $\alpha_{\mathrm{sBh}-\mathrm{d}}$. The fast $\mathrm{Bh}$ pool was constrained to a steady-state condition. The $F_{a \mathrm{t}}$ value was given by the topsoil horizon modelling. The $C$ flux from topsoil to the fast $\mathrm{Bh}$ pool was set at $1 \mathrm{~g} \mathrm{~m}^{-2}$ year $^{-1}$, to get a total $\mathrm{C}$ flux from the topsoil to $\mathrm{Bh}$ horizons close to the value obtained by Sierra et al. (2013) $\left(2.1 \mathrm{~g} \mathrm{~m}^{-2}\right.$ year $\left.^{-1}\right)$. The size of the present-day observed fast $\mathrm{Bh}\left(C_{\mathrm{fBh}}\right)$ was arbitrarily set at $5 \%$ of the total $\mathrm{Bh}$ (see above). The presentday output flux from $\mathrm{Bh}$ to deep horizons was constrained to 0.58 and $0.05 \mathrm{gC} \mathrm{m}^{-2}$ year $^{-1}$ for the fast and slow $\mathrm{Bh}$ pools, respectively, in order to have a sufficient flux to deep horizon without zeroing the flux from the slow Bh to the river to account for the export to the river of very humified OM, as observed by Bardy et al. (2011). As the $k_{\mathrm{fBh}}$ and the $k_{\mathrm{sBh}}$ mineralization rate had to be set below $1 \times 10^{-4}$ and $1 \times 10^{-6}$ year $^{-1}$, respectively, for solutions to be possible, values of $5 \times 10^{-5}$ and $5 \times 10^{-7}$ year $^{-1}$, respectively, were chosen. Optimizing parameters were $\alpha_{\mathrm{t}-\mathrm{sBh}}, \beta_{\mathrm{fBh}}$ and $\beta_{\mathrm{sBh}}$ and a multiple cost function minimized the differences between modelled and observed values for $C_{\mathrm{Bh}}$ and $F_{a} \mathrm{Bh}$. Results are shown in Fig. 12 and corresponding parameters in Table 4. The resulting present-day instantaneous turnover times of $\mathrm{C}$ in the whole $\mathrm{Bh}$ are 12940,16115, 67383 and $98215 \mathrm{gC}$ for profiles MAR9, DPQT, UAU4 and P7C, respectively.

\subsection{Age, carbon fluxes and carbon turnover}

Considering that the forest aboveground litter production is around $425 \mathrm{gC} \mathrm{m}^{-2} \mathrm{year}^{-1}$, the proportion of the litter aboveground $\mathrm{OM}$ produced by the forest transferred to the river network is 56, 12, 22 and $114 \%$ for profiles MAR9, DPQT, UAU4 and P7C, respectively. The high values for the MAR9 and $\mathrm{P} 7 \mathrm{C}$ profiles indicate a significant contribution of belowground litter and indicate how waterlogging of the podzol surface horizons affects the transfer of carbon from the atmosphere to dissolved organic carbon.

With regard to the Bh horizons, it should be noted that the total $\mathrm{C}$ flux leaving these horizons can be distributed in any manner between mineralization, transfer to depth and transfer to the river. However, at least two pools are required 


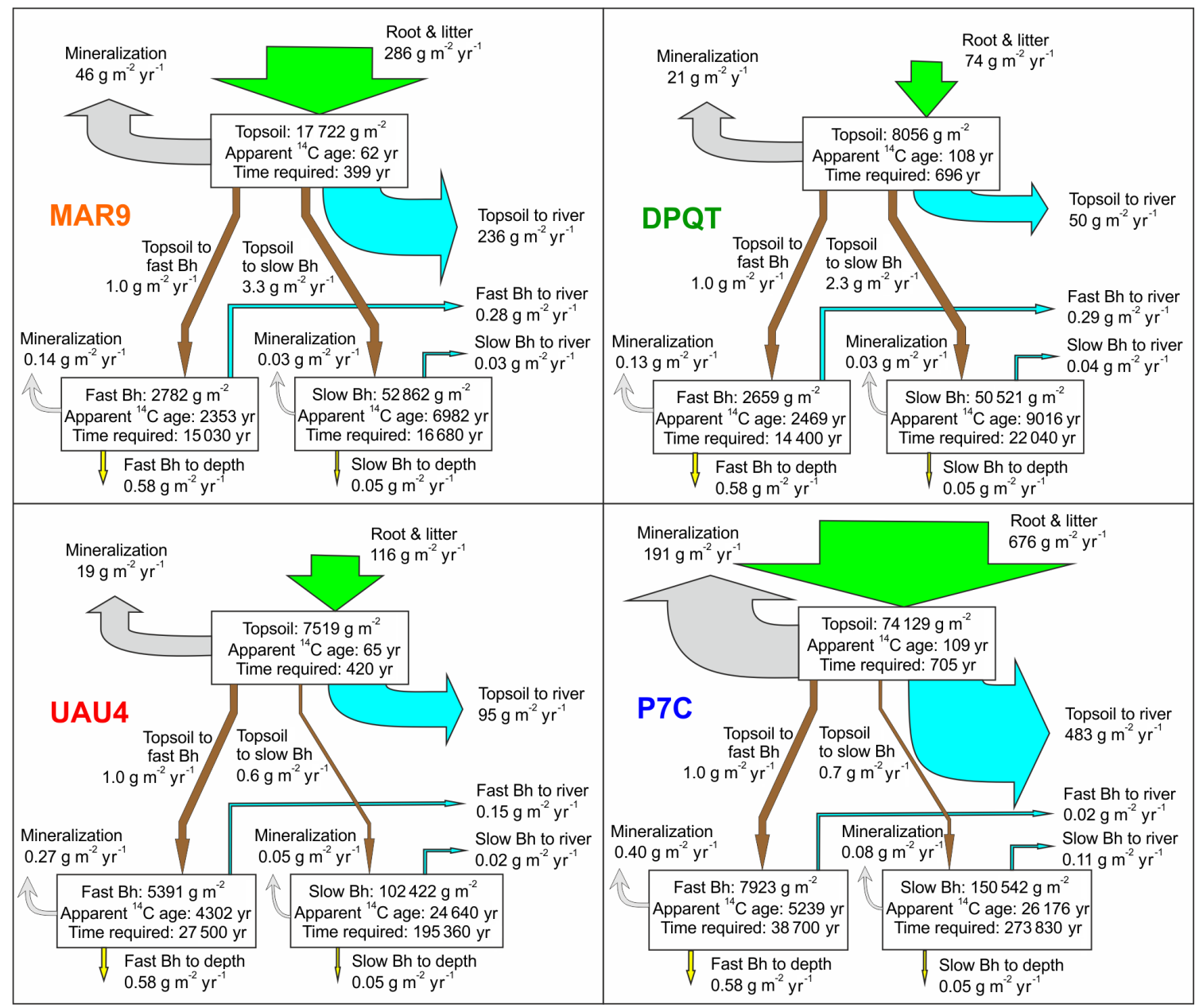

Figure 12. Modelled $\mathrm{C}$ fluxes, ${ }^{14} \mathrm{C}$ ages and $\mathrm{C}$ stock in the four studied profiles.

for the total $\mathrm{C}$ flux leaving the Bh to be sufficiently large to match the measured values. Obtaining the measured old ages requires a long genesis time (around $195 \times 10^{3}$ years for UAU4 and $274 \times 10^{3}$ years for P7C) and very small input and output carbon fluxes. Because younger profiles, such as MAR9 and DPQT, can form with higher fluxes, it is likely that the flux rates changed during the development of the profile, reducing progressively with time. Higher flux rates during the earlier periods of profile development, however, would lengthen the profile genesis time (Fig. 11), so that the genesis time estimated here for the slow Bh (around $17 \times 10^{3}, 22 \times 10^{3}, 195 \times 10^{3}$ and $274 \times 10^{3}$ for MAR9, DPQT, UAU4 and P7C, respectively) can be considered a good estimate of the minimum time required to form the presently observed soils. This is especially true for the DPQT and UAU4 profiles, as their Bh C stock value is a low estimate (cf. Sect. 2.1). Another source of overestimation of the genesis time is that, to simplify the calculations, we have not considered changes in atmospheric ${ }^{14} \mathrm{C}$ content over the past 50000 years, when it was shown that for most of this pe- riod conventional ages have to be corrected by more than $10 \%$ (Reimer et al., 2009). The estimated ages are very old when compared to temperate mature podzol that developed in $1 \times 10^{3}-6 \times 10^{3}$ years (Sauer et al., 2007; Scharpenseel, 1993).

\section{Conclusion}

Modelling the carbon fluxes by constraining both total carbon and radiocarbon was an effective tool for determining the order of magnitude of the carbon fluxes and the time of genesis of the different carbon-containing horizons. Here modelling the upper horizons separately was necessary because of numerical constraints due to the great differences in carbon turnover time between topsoil horizons and $\mathrm{Bh}$. Steady-state values obtained for the topsoil horizon could subsequently be introduced in Bh modelling. The approach we used can be applied to a wide range of situations, if necessary with simplifying assumptions to sufficiently reduce the degree of freedom of the system. 
Table 4. Parameters used for the modelling shown in Fig. 12.

\begin{tabular}{lrrrr}
\hline${\text { Rates }\left(\text { year }^{-1}\right)}$ & MAR9 & DPQT & UAU4 & P7C \\
\hline$\beta_{\mathrm{t}}$ & $1.61 \times 10^{-2}$ & $9.19 \times 10^{-3}$ & $1.54 \times 10^{-2}$ & $9.12 \times 10^{-3}$ \\
$k_{\mathrm{t}}$ & $2.57 \times 10^{-3}$ & $2.57 \times 10^{-3}$ & $2.57 \times 10^{-3}$ & $2.57 \times 10^{-3}$ \\
$\alpha_{\mathrm{t}-\mathrm{fBh}}$ & $5.64 \times 10^{-5}$ & $1.24 \times 10^{-4}$ & $1.33 \times 10^{-4}$ & $1.35 \times 10^{-5}$ \\
$\alpha_{\mathrm{t}-\mathrm{sBh}}$ & $1.85 \times 10^{-4}$ & $2.90 \times 10^{-4}$ & $8.61 \times 10^{-5}$ & $1.01 \times 10^{-5}$ \\
$\alpha_{\mathrm{t}-\mathrm{r}}$ & $1.33 \times 10^{-2}$ & $6.20 \times 10^{-3}$ & $1.26 \times 10^{-2}$ & $6.53 \times 10^{-3}$ \\
$\beta_{\mathrm{fBh}}$ & $3.59 \times 10^{-4}$ & $3.76 \times 10^{-4}$ & $1.86 \times 10^{-4}$ & $1.26 \times 10^{-4}$ \\
$k_{\mathrm{fBh}}$ & $5.00 \times 10^{-5}$ & $5.00 \times 10^{-5}$ & $5.00 \times 10^{-5}$ & $5.00 \times 10^{-5}$ \\
$\alpha_{\mathrm{fBh}-\mathrm{r}}$ & $1.01 \times 10^{-4}$ & $1.08 \times 10^{-4}$ & $2.79 \times 10^{-5}$ & $3.01 \times 10^{-6}$ \\
$\alpha_{\mathrm{fBh}-\mathrm{d}}$ & $2.09 \times 10^{-4}$ & $2.18 \times 10^{-4}$ & $1.08 \times 10^{-4}$ & $7.32 \times 10^{-5}$ \\
$\beta_{\mathrm{sBh}}$ & $2.00 \times 10^{-6}$ & $2.00 \times 10^{-6}$ & $1.20 \times 10^{-6}$ & $1.57 \times 10^{-6}$ \\
$k_{\mathrm{sBh}}$ & $5.00 \times 10^{-7}$ & $5.00 \times 10^{-7}$ & $5.00 \times 10^{-7}$ & $5.00 \times 10^{-7}$ \\
$\alpha_{\mathrm{sBh}-\mathrm{r}}$ & $6.35 \times 10^{-7}$ & $8.86 \times 10^{-7}$ & $1.83 \times 10^{-7}$ & $7.62 \times 10^{-7}$ \\
$\alpha_{\mathrm{sBh}-\mathrm{d}}$ & $9.46 \times 10^{-7}$ & $9.90 \times 10^{-7}$ & $4.88 \times 10^{-7}$ & $3.32 \times 10^{-7}$ \\
\hline
\end{tabular}

The results obtained showed that the organic matter of the podzol topsoil is very young $\left({ }^{14} \mathrm{C}\right.$ age from 62 to 109 years), with an annual $\mathrm{C}$ turnover, i.e. the carbon flux passing annually through the horizon, that increases if the topsoil is hydromorphic. This indicates that the most waterlogged zones of the podzolized areas are the main source of dissolved organic matter to the Amazonian hydrographic network.

The model suggests that the Amazonian podzols are accumulating organic $\mathrm{C}$ in the $\mathrm{Bh}$ horizons at rates ranging from 0.54 to $3.17 \mathrm{gC} \mathrm{m}^{-2}$ year $^{-1}$, equivalent to 0.005 to $0.032 \mathrm{tC} \mathrm{ha}^{-1}$ year $^{-1}$ of very stable C. Climate models predict changes in precipitation patterns, with greater frequency of dry periods, in the Amazon basin (Meehl and Solomon, 2007), possibly resulting in less frequent waterlogging. The change in precipitation patterns could have a dramatic effect on the $\mathrm{C}$ dynamics of these systems, with an increase in the mineralization of topsoil OM and an associated reduction in DOC transfer to both the deep $\mathrm{Bh}$ and the river network. It may be noted that a ${ }^{14} \mathrm{C}$ dating of the river DOC would help to determine the proportion of DOC topsoil origin and of $\mathrm{Bh}$ horizon origin. The topsoil horizons reached a steady state in less than 750 years. The organic matter in the Bh horizons was older $\left({ }^{14} \mathrm{C}\right.$ age around $7 \mathrm{kyr}$ for the younger profile and $24 \times 10^{3}$ years for the older). The study showed that it was necessary to represent the $\mathrm{Bh} \mathrm{C}$ with two $\mathrm{C}$ pools in order to replicate a number of carbon fluxes, leaving the $\mathrm{Bh}$ horizons that have been observed in previous studies. This suggests that the response of the $\mathrm{Bh}$ organic $\mathrm{C}$ to changes in water regime may be quite complex. The formation of the slow Bh pool required small input and output $\mathrm{C}$ fluxes (lower than 3.5 and $0.8 \mathrm{~g} \mathrm{~cm}^{-2}$ year ${ }^{-1}$ for the two younger and two older Bhs, respectively). Their genesis time was necessarily longer than $15 \times 10^{3}$ and $130 \times 10^{3}$ years for the two younger and two older Bhs, respectively. The time needed to reach a steady state is very long (more than $48 \times 10^{3}$ and $450 \times 10^{3}$ years, respectively) so that a steady state was prob- ably not reached. The genesis time calculated by considering the more likely settings runs around $15 \times 10^{3}-25 \times 10^{3}$ and $180 \times 10^{3}-290 \times 10^{3}$ years, respectively; the determination of these ages, which can be considered as low estimates, can help to constrain the dating of the sedimentary formations on which podzols have developed. Finally, a greater frequency of dry periods during the year might also possibly result in an increase in $\mathrm{Bh}$ mineralization rates and therefore of $\mathrm{CO}_{2}$ degassing from the $\mathrm{Bh}$; this question will be the object of a further publication.

\section{Sample availability}

IGSN registration numbers of the profiles used in this paper: IEYLU0001, IEYLU0002, IEYLU0003, and IEYLU0004.

Competing interests. The authors declare that they have no conflict of interest.

Acknowledgements. This work was funded by grants from (1) Brazilian FAPESP (São Paulo Research Foundation. Process numbers: 2011/03250-2; 2012/51469-6) and CNPq, (303478/20110; 306674/2014-9), (2) French ARCUS (joint programme of Région PACA and French Ministry of Foreign Affairs) and (3) French ANR (Agence Nationale de la Recherche, process number ANR-12-IS06-0002 “C-PROFOR”).

Edited by: V. Brovkin

Reviewed by: two anonymous referees

\section{References}

Baisden, W. T., Amundson, R., Brenner, D. L., Cook, A. C., Kendall, C., and Harden, J. W.: A multiisotope C and N modeling analysis of soil organic matter turnover and transport 
as a function of soil depth in a California annual grassland soil chronosequence, Global Biogeochem. Cy., 16, 82-1-82-26, doi:10.1029/2001GB001823, 2002.

Bardy, M., Derenne, S., Allard, T., Benedetti, M. F., and Fritsch, E.: Podzolisation and exportation of organic matter in black waters of the Rio Negro (upper Amazon basin, Brazil), Biogeochemistry, 106, 71-88, doi:10.1007/s10533-010-9564-9, 2011.

Chauvel, A., Lucas, Y., and Boulet, R.: On the genesis of the soil mantle of the region of Manaus, Central Amazonia, Brazil, Experientia, 43, 234-241, doi:10.1007/BF01945546, 1987.

Colinvaux, P. A. and De Oliveira, P. E.: Amazon plant diversity and climate through the Cenozoic, Palaeogeogr. Palaeocl., 166, 5163, doi:10.1016/S0031-0182(00)00201-7, 2001.

Cornu, C., Luizão, F. J., Rouiller, J., and Lucas, Y.: Comparative study of litter decomposition and mineral element release in two Amazonian forest ecosystems?: litter bag experiments, Pedobiologia, 41, 456-471, 1997.

Dubroeucq, D. and Volkoff, B.: From oxisols to spodosols and histosols: Evolution of the soil mantles in the Rio Negro basin (Amazonia), Catena, 32, 245-280, doi:10.1016/S03418162(98)00045-9, 1998.

Du Gardin, B.: Dynamique hydrique et biogéochimique d'un sol à porosité bimodale?: Cas des systèmes ferralsols-podzols d'Amazonie, Presses Académiques Francophones, 2015.

Horbe, A. M. C., Horbe, M. A., and Suguio, K.: Tropical Spodosols in northeastern Amazonas State, Brazil, Geoderma, 119, 55-68, doi:10.1016/S0016-7061(03)00233-7, 2004.

Leenheer, J. A.: Origin and nature of humic substances in the waters in the Amazon river basin, Acta Amaz., 10, 513-526, 1980.

Lucas, Y., Montes, C. R., Mounier, S., Loustau Cazalet, M., Ishida, D., Achard, R., Garnier, C., Coulomb, B., and Melfi, A. J.: Biogeochemistry of an Amazonian podzol-ferralsol soil system with white kaolin, Biogeosciences, 9, 3705-3720, doi:10.5194/bg-93705-2012, 2012.

Malhi, Y., Wood, D., Baker, T. R., Wright, J., Phillips, O. L., Cochrane, T., Meir, P., Chave, J., Almeida, S., Arroyo, L., Higuchi, N., Killeen, T. J., Laurance, S. G., Laurance, W. F., Lewis, S. L., Monteagudo, A., Neill, D. A., Vargas, P. N., Pitman, N. C. A., Quesada, C. A., Salomão, R., Silva, J. N. M., Lezama, A. T., Terborgh, J., Martínez, R. V., and Vinceti, B.: The regional variation of aboveground live biomass in old-growth Amazonian forests, Glob. Change Biol., 12, 1107-1138, doi:10.1111/j.13652486.2006.01120.x, 2006.

Meehl, G. and Solomon, S.: Climate Change 2007: The Physical Science Basis, Cambridge University Press, 2007.

Menichetti, L., Kätterer, T., and Leifeld, J.: Parametrization consequences of constraining soil organic matter models by total carbon and radiocarbon using long-term field data, Biogeosciences, 13, 3003-3019, doi:10.5194/bg-13-3003-2016, 2016.

Montes, C. R., Lucas, Y., Pereira, O. J. R., Achard, R., Grimaldi, M., and Melfi, A. J.: Deep plant-derived carbon storage in Amazonian podzols, Biogeosciences, 8, 113-120, doi:10.5194/bg-8113-2011, 2011.

NIWA: Data set, Natl. Inst. Water Atmos. Res. New Zeal., available at: http://ds.data.jma.go.jp/gmd/wdcgg/pub/data/current/14co2/ event/bhd541s00.niwa.as.ot.14co2.nl.ev.dat (last access: 5 December 2016), 2016.

Proctor, J.: NPP Tropical Forest: Gunung Mulu, Malaysia, 19771978, R1. Data set, Oak Ridge Natl. Lab. Distrib. Act. Arch. Cen- ter, Oak Ridge, Tennessee, USA, doi:10.3334/ORNLDAAC/474, 2013.

Raymond, P. A.: Carbon cycle: the age of the Amazon's breath, Nature, 436, 469-470, doi:10.1038/436469a, 2005.

Reimer, P. J., Baillie, M. G. L., Bard, E., Bayliss, A., Beck, J. W., Blackwell, P. G., Bronk Ramsey, C., Buck, C. E., Burr, G. S., Edwards, R. L., Friedrich, M., Grootes, P. M., Guilderson, T. P., Hajdas, I., Heaton, T. J., Hogg, A. G., Hughen, K. A., Kaiser, K. F., Kromer, B., McCormac, F. G., Manning, S. W., Reimer, R. W., Richards, D. A., Southon, J. R., Talamo, S., Turney, C. S. M., van der Plicht, J., and Weyhenmeyer, C. E.: IntCal09 and Marine09 radiocarbon age calibration curves, $0-50,000$ years cal BP, Radiocarbon, 51, 1111-1150, doi:10.1017/S0033822200034202, 2009.

Sauer, D., Sponagel, H., Sommer, M., Giani, L., Jahn, R., and Stahr, K.: Podzol: Soil of the year 2007. A review on its genesis, occurrence, and functions, J. Plant Nutr. Soil Sci., 170, 581-597, doi:10.1002/jpln.200700135, 2007.

Schaetzl, R. J. and Rothstein, D. E.: Temporal variation in the strength of podzolization as indicated by lysimeter data, Geoderma, 282, 26-36, doi:10.1016/j.geoderma.2016.07.005, 2016.

Scharpenseel, H. W.: Major carbon reservoirs of the pedosphere; source - sink relations; potential of $\mathrm{D}^{14} \mathrm{C}$ and $\delta^{13} \mathrm{C}$ as supporting methodologies, Water Air Soil Poll., 70, 431-442, doi:10.1007/BF01105014, 1993.

Schwartz, D.: Some podzols on Bateke sands and their origins, People's Republic of Congo, Geoderma, 43, 229-247, doi:10.1016/0016-7061(88)90045-6, 1988.

Sierra, C. A., Jiménez, E. M., Reu, B., Peñuela, M. C., Thuille, A., and Quesada, C. A.: Low vertical transfer rates of carbon inferred from radiocarbon analysis in an Amazon Podzol, Biogeosciences, 10, 3455-3464, doi:10.5194/bg-10-3455-2013, 2013.

Sierra, C. A., Müller, M., and Trumbore, S. E.: Modeling radiocarbon dynamics in soils: SoilR version 1.1, Geosci. Model Dev., 7, 1919-1931, doi:10.5194/gmd-7-1919-2014, 2014.

Stuiver, M. and Polach, H. A.: Radiocarbon discussion reporting of ${ }^{14} \mathrm{C}$ data, Forensic Sci. Int., 19, 355-363, 1977.

Tardy, Y., Roquin, C., Bustillo, V., Moreira, M., Martinelli, L. A., and Victoria, R.: Carbon and Water Cycles Amazon River Basin Applied Biogeochemistry, Atlantica, Biarritz, France, 2009.

Tipping, E., Chamberlain, P. M., Fröberg, M., Hanson, P. J., and Jardine, P. M.: Simulation of carbon cycling, including dissolved organic carbon transport, in forest soil locally enriched with ${ }^{14} \mathrm{C}$, Biogeochemistry, 108, 91-107, doi:10.1007/s10533-011-9575$1,2012$.

Trumbore, S.: Age of Soil Organic Matter and Soil Respiration: Radiocarbon Constraints on Belowground C Dynamics, Ecol. Appl., 10, 399-411, doi:10.1890/10510761(2000)010[0399:AOSOMA]2.0.CO;2, 2000.

Van der Hammen, T. and Hooghiemstra, H.: Neogene and Quaternary History of Vegetation, Climate, and Plant Diversity in Amazonia, Quaternary Sci. Rev., 19, 725-742, doi:10.1016/S02773791(99)00024-4, 2000.

Van Hees, P. A. W., Johansson, E., and Jones, D. L.: Dynamics of simple carbon compounds in two forest soils as revealed by soil solution concentrations and biodegradation kinetics, Plant Soil., 310, 11-23, doi:10.1007/s11104-008-9623-3, 2008.

Wanner, H.: Soil Respiration, Litter Fall and Productivity of Tropical Rain Forest, J. Ecol., 58, 543, doi:10.2307/2258289, 1970. 